\title{
Uncertainties from a worldwide survey on antiepileptic drug withdrawal after seizure remission
}

Luca Bartolini, MD, Shahram Majidi, MD, and Mohamad Z. Koubeissi, MD

Neurology: Clinical Practice April 2018 vol. 8 no. 2 108-115 doi:10.1212/CPJ.0000000000000441
Correspondence

Dr. Bartolini

luca.bartolini@nih.gov

\section{Abstract \\ Background}

We sought to determine differences in practice for discontinuation of antiepileptic drugs (AEDs) after seizure remission and stimulate the planning and conduction of withdrawal trials.

\section{Methods}

We utilized a worldwide electronic survey that included questions about AED discontinuation for 3 paradigmatic cases in remission: (1) focal epilepsy of unknown etiology, (2) temporal lobe epilepsy after surgery, and (3) juvenile myoclonic epilepsy. We analyzed 466 complete questionnaires from 53 countries, including the United States. Statistical analysis included $\chi^{2}$ and multivariate logistic regression.

\section{Results}

Case 1: responders in practice for $<10$ years were less likely to taper AEDs: odds ratio (OR) (95\% confidence interval $[\mathrm{CI}]) 0.52(0.32-0.85), p=0.02$. The likelihood of stopping AEDs was higher among doctors treating children: OR (95\% CI): $11.41(2.51-40.13), p=0.002$. Doctors treating children were also more likely to stop after 2 years or less of remission: OR (95\% CI): $6.91(2.62-19.31), p=0.002$, and the same was observed for US physicians: OR (95\% CI): $1.61(1.01-2.57), p=0.0049$. Case 2 : responders treating children were more likely to taper after 1 year or less of postoperative remission, with the goal of discontinuing all medications: OR (95\% CI): 1.91 (1.09-3.12), $p=0.015$, and so were US-based responders: OR (95\% CI): $1.73(1.21-2.41), p=0.003$. Case 3: epileptologists were less likely to withdraw the medication: OR (95\% CI): $0.56(0.39-0.82), p=0.003$, and so were those in practice for 10 or more years: OR (95\% CI): $0.54(0.31-0.95), p=0.025$.

\section{Conclusions}

We observed several differences in practice for AED withdrawal after seizure remission that highlight global uncertainty. Trials of AED discontinuation are needed to provide evidencebased guidance.

Discontinuation of antiepileptic drugs (AEDs) after remission of epilepsy has been the subject of debate for decades ${ }^{1,2}$ and is often considered an individualized decision. Many factors need to be taken into account, including, among others, syndromic classification of epilepsy, degree of seizure control, imaging and EEG findings, genetic testing when

\section{MORE ONLINE}

Explore this topic

NPub.org/NCP/pc3

Interactive world map

NPub.org/NCP/map03

More Practice Current

NPub.org/NCP/

practicecurrent

Clinical Epilepsy Section (LB) and Stroke Diagnostics and Therapeutics Section (SM), National Institute of Neurological Disorders and Stroke, Bethesda, MD; Center for Neuroscience (LB), George Washington University, Children's National Health System; and Department of Neurology (SM, MZK), George Washington University Hospital, Washington, DC.

Funding information and disclosures are provided at the end of the article. Full disclosure form information provided by the authors is available with the full text of this article at Neurology.org/cp. 
As a first step towards stimulating the planning and conduction of

\section{withdrawal trials, we aimed to determine differences in practice for discontinuation of AEDs worldwide.}

appropriate, surgical pathology reports if applicable, monotherapy vs polypharmacy with AEDs, presence of medication adverse events, and patient preference.

The optimal duration of seizure freedom needed before considering AED discontinuation and the tapering rate remain unknown. ${ }^{3}$ Here, as a first step towards stimulating the planning and conduction of withdrawal trials, we aimed to determine differences in practice for discontinuation of AEDs worldwide. We presented scenarios of focal epilepsy of unknown etiology, temporal lobe epilepsy after surgery, and juvenile myoclonic epilepsy.

\section{Methods}

\section{Survey}

We utilized an electronic survey that included 4 clinical and 7 demographic questions (appendix e-1, links.lww.com/ $\mathrm{CPJ} / \mathrm{A} 20$ ). The clinical questions pertained to 3 separate cases: (1) A 14-year-old boy with a 7-year history of focal epilepsy (FE) of unknown etiology, seizure- and aura-free for the last 6 months on a maximized dose of oxcarbazepine; the questions targeted decision and timing of AED discontinuation and recommended tests before starting the taper. (2) A 35-year-old man diagnosed with temporal lobe epilepsy at age 18 , refractory to dual therapy with carbamazepine and levetiracetam, who underwent temporal lobectomy, and was found to have focal cortical dysplasia, and has been seizure-free for 6 months postoperatively; the questions were about the timing of initiation of AED withdrawal and about long-term monotherapy vs no therapy. (3) A 19-year-old man diagnosed 1 year prior with juvenile myoclonic epilepsy (JME) who became seizurefree on valproic acid; the question was regarding the decision and timing of AED discontinuation.

Demographic questions included population treated (adults, children, or both); subspecialty of the surveyed physicians-neurophysiologist/epileptologist or not; years in practice; primary work setting; level of training; practice located in the United States or abroad; and in what US state or country. The survey was available online and was anonymous. Participation did not require membership in the American Academy of Neurology (AAN) or subscription to AAN journals. No compensation was offered. A link to the questionnaire was available in the Neurology journals webpages, in online ads and the print version of the journals, and in the Practice Current dedicated webpage of Neurology Clinical Practice. ${ }^{4}$ The survey was also advertised by the AAN and Neurology journals via social media. Individual Internet protocol address was collected to ensure authenticity of responses. We opened the survey from September 13, 2016, to February 28, 2017, and recorded a total of 1,202 accesses. A total of 466 complete questionnaires (where all questions were answered) were included in the analysis. The study was certified as exempt from review by Children's National Health System institutional review board.

\section{Statistical analysis}

Frequency of the responses for each question/scenario was calculated in 4 different demographic groups, including (1) practice level (trainee, $<10$-year experience, $\geq 10$-year experience), (2) subspecialty training status (epileptologist vs nonepileptologist), (3) practice population (children, adults, or both), and (4) practice location (United States vs abroad). The $\chi^{2}$ test was used for categorical data with a $p$ value $<0.05$ considered statistically significant. After identifying significant differences between the groups on univariate analysis, multivariate logistic regression was performed to adjust for all confounding variables. All analyses were performed using SAS 9.3 software (SAS Institute, Cary, NC).

\section{Results}

We collected a total of 466 completed questionnaires from 53 countries, including the United States. Of the responders, $62(13 \%)$ treated children, $301(65 \%)$ adults, and 103 (22\%) both. The majority $(\mathrm{n}=228,50 \%)$ had been in practice for 10 or more years, $165(36 \%)$ for less than 10 years, and $67(14 \%)$ were still in training. Neurophysiologists or epileptologists $(216,46 \%)$ constituted a comparable subset to nonepileptologists (251, 54\%). More than half of the responders $(n=252,54 \%)$ practiced outside of the United States. Ninety (36\%) were from Europe, 75 (30\%) from Asia, 48 (19\%) from South America, 24 (9\%) from Canada/Central America, 8 (3\%) from Africa, and 7 (3\%) from Australia.

For case 1, a higher proportion of those who treated children $(\mathrm{n}=59 / 61,97 \%)$ recommended tapering the medication than those treating adults only $(n=232 / 301,77 \%)$, or those treating both adults and children $(\mathrm{n}=77 / 103$, $75 \%)\left(\chi^{2}[2]=13.4, p=0.001\right)$. Responders in practice for less than 10 years were less likely to withdraw the medication $\left(\chi^{2}[2]=6.8, p=0.032\right)$ (table 1$)$. In multivariate analysis, using combined responses from trainees and doctors in practice for $>10$ years as a reference group, the likelihood to withdraw the AED was lower among doctors in practice for $<10$ years after adjusting for practice location, population treated, and subspecialty: $73 \%$ vs $83 \%$ with 
Table 1 Differences in decision to withdraw antiepileptic drugs (AEDs) in focal epilepsy of unknown etiology based on demographic variables

\begin{tabular}{|c|c|c|c|}
\hline & $\begin{array}{l}\text { AED withdrawal, } \\
\text { yes, } n=369(79 \%) \text {, } \\
n(\%)\end{array}$ & $\begin{array}{l}\text { AED } \\
\text { withdrawal, } \\
\text { no, } n=97(21 \%) \text {, } \\
n(\%)\end{array}$ & $p$ Value \\
\hline Subspecialty & & & 0.33 \\
\hline Epileptologist & $166(77)$ & $49(23)$ & \\
\hline Nonepileptologist & $203(81)$ & $48(19)$ & \\
\hline Years in practice & & & $0.032 *$ \\
\hline Trainee & $55(82)$ & $12(18)$ & \\
\hline$<10$ & $120(73)$ & $45(27)$ & \\
\hline$\geq 10$ & $189(83)$ & $38(18)$ & \\
\hline Population treated & & & $0.001^{* *}$ \\
\hline Children & $59(97)$ & $2(3)$ & \\
\hline Adults & $232(77)$ & $69(23)$ & \\
\hline Both & $77(75)$ & $26(25)$ & \\
\hline Practice location & & & 0.27 \\
\hline United States & $165(77)$ & $49(23)$ & \\
\hline Outside of United States & $204(81)$ & $47(19)$ & \\
\hline $\begin{array}{l}* p \leq 0.05 . \\
* * p \leq 0.001 .\end{array}$ & & & \\
\hline
\end{tabular}

odds ratio (OR) (95\% confidence interval $[\mathrm{CI}]) 0.59$ (0.37-0.95), $p=0.03$. Similarly, using the combined response from doctors treating adults and doctors treating both adults and children as a reference group, the likelihood of stopping the medication remained higher among doctors treating children after adjusting for practice location, years in practice, and subspecialty: $97 \%$ vs $77 \%$ (OR [95\% CI] 10.21 [2.24-43.04]), $p=0.002$.

Among those who agreed to taper, 234 (63\%) opted to do so after less than 2 years of seizure remission and 136 (37\%) after 2 or more years (table 2). Of those treating children, $54 / 59$ (92\%) chose to withdraw after less than 2 years, a higher percentage compared with responders treating adults $(\mathrm{n}=133 / 232,57 \%)$ or both adults and children $(\mathrm{n}=$ $45 / 77,58 \%)\left(\chi^{2}[2]=24.5, p<0.0001\right)$. Similarly, US physicians were more likely to taper after less than 2 years ( $\mathrm{n}$ $=118 / 165,72 \%)$ compared with non-US responders $(\mathrm{n}=$ $115 / 204,56 \%)\left(\chi^{2}[1]=9.0, p=0.003\right)$.

In a multivariate regression model, using combined responses from physicians treating adults and physicians treating both adults and children as reference group, survey takers treating only children were still more likely to stop the AED in $\leq 2$ years after adjusting for practice location, subspecialty, and years in practice: $92 \%$ vs $58 \%$ (OR [95\% CI] $6.91[2.62-19.31]), p=$
0.002. Similarly, US physicians were more likely to stop in less than 2 years after adjusting for subspecialty, practice level, and population treated: $72 \%$ vs $56 \%$ (OR $[95 \%$ CI $] 1.68$ $[1.06-2.67]), p=0.03$. Among the tapering group, $78(21 \%)$ would request no test, $9(2 \%)$ would request just a brain MRI, 197 (53\%) an EEG, and 86 (23\%) both MRI and EEG prior to tapering (table 3). The main difference consisted of trainees requesting both tests more frequently than other practice groups $\left(\chi^{2}[6]=29.0, p<0.0001\right)$.

For case 2: 211 (45\%) responders chose to taper after 6-12 months of seizure remission with the goal of no therapy, 110 (24\%) chose to taper after 6-12 months with the goal of chronic monotherapy, 87 (29\%) decided to taper after 2 years with goal of no therapy, and 55 (12\%) decided to taper after 2 years with the goal of chronic monotherapy (table 4). Responders treating children opted to taper after 1 year or less with the goal of no therapy more frequently than the other groups: $38 / 61(62 \%)$ vs $123 / 300$ (41\%) for those treating adults only, and 49/101 (48\%) for responders treating both populations $\left(\chi^{2}[8]=17.0\right.$, $p=0.03$ ). US-based survey takers chose to withdraw after 1 year or less with the same goal of no therapy more frequently than non-US practitioners: $115 / 212$ (54\%) vs $96 / 250$ (38\%) $\left(\chi^{2}[4]=17.8, p=0.0013\right)$. The same observations were confirmed by multivariate analysis (using combined response from physicians treating adults and physicians treating both adults and children as reference group), with responders treating children being more likely to taper after 1 year or less with the goal of no therapy; $62 \%$ vs $43 \%$ (OR [95\% CI] 1.91 [1.09-3.12]), $p=$ 0.015 , and US-based responders more likely to withdraw after 1 year or less with the goal of no therapy: $54 \%$ vs $38 \%$ (OR [ $95 \%$ CI] $1.73[1.21-2.41]), p=0.003$.

For case 3, 257 responders (56\%) did not recommend tapering the AED, while 206 (44\%) recommended AED discontinuation (table 5). Epileptologists were less likely to taper $(78 / 214,36 \%)$ vs nonepileptologists $(128 / 249,51 \%)\left(\chi^{2}[1]=10.4, p=0.001\right)$; so were responders in practice for 10 years or more compared with the other groups $\left(\chi^{2}[2]=7.3, p=0.02\right)$. In a multivariate logistic regression model, after adjusting for practice location, population treated, practice level, and subspecialty, being an epileptologist and being in practice for $\geq 10$ years remained as independent predictors of decision, with epileptologists proving less likely to withdraw the medication after adjustment compared to nonepileptologists: $36 \%$ vs $51 \%$ (OR [95\% CI] 0.56; [0.39-0.82]), $p=0.003$, and those in practice for 10 or more years less likely to taper compared to physicians in practice $<10$ years and trainees: $40 \%$ vs $51 \%$ (OR [ $[95 \% \mathrm{CI}]$ 0.54; [0.31-0.95]), $p=0.025$.

Among those who recommended AED discontinuation in JME in remission, 98 (48\%) opted stopping after 2 years of seizure freedom and 108 (52\%) after 3 years or more, with no differences across groups (table 6).

In an in-depth analysis of all accesses to the survey, we found that $580 / 1,202(48 \%)$ people who opened it did not provide any 
Table 2 Differences in early vs late antiepileptic drug (AED) taper in focal epilepsy of unknown etiology based on demographic variables

\begin{tabular}{|c|c|c|c|}
\hline & $\begin{array}{l}\text { Start AED withdrawal after } \\
\leq 2 \text { y of seizure remission, } \\
n=234(63 \%), n(\%)\end{array}$ & $\begin{array}{l}\text { Start AED withdrawal after } \\
>2 \text { y of seizure remission, } \\
n=136(37 \%), n(\%)\end{array}$ & $p$ Value \\
\hline Subspecialty & & & 0.08 \\
\hline Epileptologist & $113(68)$ & $53(32)$ & \\
\hline Nonepileptologist & $120(59)$ & $83(41)$ & \\
\hline Practice level, y & & & 0.07 \\
\hline Trainee & $29(53)$ & $26(47)$ & \\
\hline$<10$ & $84(70)$ & $36(30)$ & \\
\hline$\geq 10$ & $115(61)$ & $74(39)$ & \\
\hline Population treated & & & $<0.0001$ * \\
\hline Children & $54(92)$ & $5(8)$ & \\
\hline Adults & $133(57)$ & $99(43)$ & \\
\hline Both & $45(58)$ & $32(42)$ & \\
\hline Practice location & & & $0.003^{\star \star}$ \\
\hline United States & $118(72)$ & $47(28)$ & \\
\hline Outside of United States & $115(56)$ & $89(44)$ & \\
\hline $\begin{array}{l}* p \leq 0.0001 \\
* * p \leq 0.01\end{array}$ & & & \\
\hline
\end{tabular}

Table 3 Differences in recommended tests prior to starting antiepileptic drug (AED) taper in focal epilepsy of unknown etiology based on demographic variables

\begin{tabular}{|c|c|c|c|c|c|}
\hline & $\begin{array}{l}\text { No test prior to AED taper, } \\
n=78(21 \%), n(\%)\end{array}$ & $\begin{array}{l}\text { EEG prior to AED taper, } \\
\mathrm{n}=197(53 \%), \mathrm{n}(\%)\end{array}$ & $\begin{array}{l}\text { MRI prior to AED taper, } \\
n=9(2 \%), n(\%)\end{array}$ & $\begin{array}{l}\mathrm{EEG}+\mathrm{MRI} \text { prior to AED } \\
\text { taper, } \mathrm{n}=86(23 \%), \mathrm{n}(\%)\end{array}$ & $p$ Value \\
\hline Subspecialty & & & & & 0.46 \\
\hline Epileptologist & $36(22)$ & $94(57)$ & $4(2)$ & $32(19)$ & \\
\hline Nonepileptologist & $41(20)$ & $103(51)$ & $5(2)$ & $54(27)$ & \\
\hline Practice level, y & & & & & $<0.0001$ \\
\hline Trainee & $8(15)$ & $22(40)$ & $1(2)$ & $24(44)$ & \\
\hline$<10$ & $24(20)$ & $57(48)$ & $7(6)$ & $32(27)$ & \\
\hline$\geq 10$ & $45(24)$ & $113(60)$ & $1(1)$ & $30(16)$ & \\
\hline Population treated & & & & & 0.33 \\
\hline Children & $18(31)$ & $2(3)$ & $28(48)$ & $11(19)$ & \\
\hline Adults & $48(21)$ & $4(2)$ & $124(53)$ & $56(24)$ & \\
\hline Both & $11(14)$ & $3(4)$ & $44(57)$ & $19(25)$ & \\
\hline Practice location & & & & & 0.46 \\
\hline United States & $36(22)$ & $4(2)$ & $93(56)$ & $32(19)$ & \\
\hline Outside of United States & $41(20)$ & $5(2)$ & $104(51)$ & $54(26)$ & \\
\hline
\end{tabular}

$* p \leq 0.0001$ 
Our worldwide survey highlights

many discrepancies in strategies of

AED tapering after seizure remission, which reflects lack of evidence for

optimal practices in most types of

epilepsy.

answers. Of the remaining 622 questionnaires where at least 1 answer was provided, 97 recorded a response only to the first case about AED withdrawal in FE of unknown etiology but did not provide any other data: $12(12 \%)$ chose to taper after 1 year of seizure freedom, 34 (35\%) after 2 years, 33 (34\%) after 3-5 years, and $18(18 \%)$ chose not to taper the AED. Of 525 remaining questionnaires, 466 included answers to all 3 cases and demographic data and 59 did not have demographic data.

\section{Discussion}

Our worldwide survey highlights many discrepancies in strategies of AED tapering after seizure remission, which reflects lack of evidence for optimal practices in most types of epilepsy.
Patients with FE have traditionally been considered at higher risk of recurrence after AED withdrawal. ${ }^{5}$ The majority of available studies did not exclude patients with structural or genetic etiologies, thus generating heterogeneous results. A Cochrane review $^{3}$ included 5 trials representing 924 randomized children under 16 years of age with epilepsy, with a median follow-up of 5.6 years. Two of the studies were nonblinded with 250 children with $\mathrm{FE}$ who were randomized into early ( $<2$ years) and late $(2$ or more years) withdrawal cohorts. One of these trials excluded only patients with cerebral palsy, intellectual disability, or epileptic encephalopathies, ${ }^{6}$ and the other study included only patients with FE of unknown etiology. ${ }^{7}$ Pooled risk ratio for these 2 studies was 1.51 (95\% CI 0.97-2.35, $p=0.07){ }^{3}$, suggesting no difference in seizure recurrence after 2 years of remission. A randomized, double-blind, controlled trial of AED discontinuation in adult patients with FE (the majority of unknown etiology) in remission for $>2$ years enrolled 160 participants, randomized them to AED taper vs continuation, and concluded that recurrence occurred more frequently in the first 6-9 months after tapering. ${ }^{8}$ In a study that analyzed 82 individuals with childhood-onset cryptogenic $\mathrm{FE},{ }^{9}$ seizure relapse rate did not correlate with the duration of remission before starting the AED taper. In our survey, neurologists in practice for less than 10 years and those taking care of children favored an early taper and did not seem to agree with the 2-year minimum remission cutoff. Also, having a normal EEG right before considering the medication withdrawal was the most frequent requirement for the majority of responders with no differences

Table 4 Differences in timing of antiepileptic drug (AED) withdrawal after temporal lobectomy based on demographic variables

\begin{tabular}{|c|c|c|c|c|c|}
\hline & $\begin{array}{l}\text { Taper after } \leq 1 \text { y, goal } \\
\text { no therapy, } n=211(45 \%) \text {, } \\
n(\%)\end{array}$ & $\begin{array}{l}\text { Taper after } \leq 1 \text { y, goal } \\
\text { monotherapy, } n=110 \\
(24 \%), n(\%)\end{array}$ & $\begin{array}{l}\text { Taper after } \geq 2 \text { y, goal } \\
\text { no therapy, } n=87(29 \%) \text {, } \\
\text { n (\%) }\end{array}$ & $\begin{array}{l}\text { Taper after } \geq 2 \mathrm{y} \text {, goal } \\
\text { monotherapy, } \\
\mathrm{n}=55(12 \%), \mathrm{n}(\%)\end{array}$ & $p$ Value \\
\hline Subspecialty & & & & & 0.15 \\
\hline Epileptologist & $102(48)$ & $40(19)$ & $44(21)$ & $28(13)$ & \\
\hline Nonepileptologist & $109(44)$ & $70(28)$ & $43(17)$ & $27(11)$ & \\
\hline Practice level, y & & & & & 0.81 \\
\hline Trainee & $29(43)$ & $20(30)$ & $12(18)$ & $6(9)$ & \\
\hline$<10$ & $78(47)$ & $35(21)$ & $32(19)$ & $19(12)$ & \\
\hline$\geq 10$ & $103(46)$ & $52(23)$ & $40(18)$ & $30(13)$ & \\
\hline Population treated & & & & & $0.03 *$ \\
\hline Children & $38(62)$ & $9(15)$ & $6(10)$ & $8(13)$ & \\
\hline Adults & $123(41)$ & $81(27)$ & $63(21)$ & $33(11)$ & \\
\hline Both & $49(48)$ & $20(20)$ & $18(18)$ & $14(14)$ & \\
\hline Practice location & & & & & $0.0013^{* x}$ \\
\hline United States & $115(54)$ & $36(17)$ & $42(20)$ & $19(9)$ & \\
\hline Outside of United States & $96(38)$ & $74(30)$ & $45(18)$ & 35 (14) & \\
\hline
\end{tabular}


Table 5 Differences in decision to discontinue antiepileptic drug (AED) in juvenile myoclonic epilepsy (JME) in remission based on demographic variables

\begin{tabular}{|c|c|c|c|}
\hline & $\begin{array}{l}\text { JME in remission } \\
\text { AED taper yes, } \\
n=206(44 \%), \\
n(\%)\end{array}$ & $\begin{array}{l}\text { JME in remission } \\
\text { AED taper no, } \\
n=257(56 \%) \\
n(\%)\end{array}$ & $p$ Value \\
\hline Subspecialty & & & $0.001 *$ \\
\hline Epileptologist & $78(36)$ & $136(64)$ & \\
\hline Nonepileptologist & $128(51)$ & $121(49)$ & \\
\hline Practice level, y & & & $0.03^{* *}$ \\
\hline Trainee & $39(58)$ & $28(42)$ & \\
\hline$<10$ & $76(46)$ & $89(54)$ & \\
\hline$\geq 10$ & $89(40)$ & $135(60)$ & \\
\hline Population treated & & & 0.99 \\
\hline Children & $28(45)$ & $34(55)$ & \\
\hline Adults & $133(44)$ & $166(56)$ & \\
\hline Both & $45(45)$ & $56(55)$ & \\
\hline Practice location & & & 0.51 \\
\hline United States & $91(43)$ & $121(57)$ & \\
\hline Outside of United States & $115(46)$ & $135(54)$ & \\
\hline $\begin{array}{l}* p \leq 0.001 \\
* * p \leq 0.05\end{array}$ & & & \\
\hline
\end{tabular}

across groups, which is based on some evidence in the literature. $^{10}$

Similarly, practices of AED withdrawal after successful epilepsy surgery vary widely. Previous surveys reported that American neurologists utilized a 2-year seizure freedom requirement before considering the taper. ${ }^{11}$ Ten years after this study, we observed that survey takers, and particularly US practitioners, were inclined to start the taper after only 1 year or less of remission. While this may indicate a higher propensity for earlier AED tapering, potentially dictated by observations that early postoperative seizures predicted seizure recurrence, an evidencebased cutoff duration continues to be elusive. A 2008 expert commentary ${ }^{1}$ concluded that the best available evidence regarding AED withdrawal after epilepsy surgery consisted of 24 Class IV studies, which could not support any clinical practice recommendations. A study from the Mayo Clinic ${ }^{12}$ retrospectively analyzed 210 patients, of whom $89 \%$ had temporal lobe epilepsy, who became seizure- and aura-free for more than 1 year after surgery. The authors concluded that seizure recurrence was unrelated to the duration of the seizure-free postoperative AED treatment. A similar study ${ }^{13}$ retrospectively examined 325 patients and followed them for 10 years after temporal lobectomy. The analysis revealed that patients with 2 years of postoperative seizure freedom had a $74 \%$ probability (95\% CI $66-81$ ) of continued seizure freedom by 10 postoperative years
Table 6 Differences in early vs late antiepileptic drug (AED) taper in juvenile myoclonic epilepsy (JME) in remission based on demographic variables

\begin{tabular}{|c|c|c|c|}
\hline & $\begin{array}{l}\text { JME in remission } \\
\text { taper in } \leq 2 \mathrm{y} \\
\mathrm{n}=98(48 \%) \\
\mathrm{n}(\%)\end{array}$ & $\begin{array}{l}\text { JME in remission } \\
\text { taper in }>2 \mathrm{y} \\
\mathrm{n}=108(52 \%) \\
\mathrm{n}(\%)\end{array}$ & $p$ Value \\
\hline Subspecialty & & & 0.79 \\
\hline Epileptologist & $38(49)$ & $40(51)$ & \\
\hline Nonepileptologist & $68(47)$ & $68(53)$ & \\
\hline Practice level, y & & & 0.80 \\
\hline Trainee & $18(46)$ & $18(46)$ & \\
\hline$<10$ & $38(50)$ & $38(50)$ & \\
\hline$\geq 10$ & $40(45)$ & $49(55)$ & \\
\hline Population treated & & & 0.07 \\
\hline Children & $19(68)$ & $9(32)$ & \\
\hline Adults & $59(44)$ & $74(56)$ & \\
\hline Both & $20(44)$ & $25(56)$ & \\
\hline Practice location & & & 0.18 \\
\hline United States & $48(53)$ & $43(47)$ & \\
\hline Outside of United States & $50(43)$ & $65(57)$ & \\
\hline
\end{tabular}

and that AED withdrawal after 2 postoperative years was not associated with an increased risk of recurrence (hazard ratio 1.03, 95\% CI 0.5-2.1). Prospective data on 301 patients from the Multicenter Study of Epilepsy Surgery published in $2006^{14}$ revealed that about one third of patients who had 1 year of seizure remission after surgery eventually experienced a relapse after they attempted to withdraw their AEDs. After adjusting for immediate vs delayed remission after hospital discharge, no effect of drug reduction on the rate of relapse was noted compared with patients who continued their medications.

A retrospective analysis of 97 pediatric patients who underwent epilepsy surgery and were aura- and seizure-free for more than 6 months after the procedure found that stopping AEDs after 12 months of remission was not associated with higher risk of recurrence than withdrawing after 24 months. ${ }^{15}$ Our data concerning responses from survey takers whose practice was limited to children seem to support this.

JME is generally considered a lifelong form of epilepsy, albeit usually responsive to medications. AEDs are commonly continued indefinitely, ${ }^{16}$ based on studies that showed a high risk of seizure recurrence after AED tapering. ${ }^{17}$ Conversely, studies with decades-long follow-up revealed that not all patients with JME in remission have recurrence of seizures or disabling seizures after discontinuing the medications. In a study of 23 patients with JME, at the end of a 20-year follow-up, 11 were off medication and of them 6 had no seizures, 3 had only myoclonus, and 2 had rare seizures. ${ }^{18}$ Another study followed 31 
patients with JME for more than 25 years and found that of the 21 patients who became seizure-free, 6 were off medications and had no recurrence. ${ }^{19}$ Another study reported seizure remission in $60 \%$ of 66 patients; 11 were off medication for more than 5 years at a median follow-up of 45 years. ${ }^{20}$

In our survey, it was unsurprising to see that epileptologists and more senior neurologists were reticent to discontinue AEDs in JME, but it was striking to observe that $50 \%$ of nonsubspecialty-trained neurologists did recommend to stop the medication. While many patients with JME may be seen in clinic by epileptologists, it is not far-fetched to assume that many of them are actually seen by general neurologists, even in the United States. A potential conclusion would be that previously published studies primarily included cohorts followed by epileptologists and therefore are skewed towards higher proportions of individuals on chronic medication, while the reality could be that many neurologists at some point stop the medication and simply do not report the outcome of their patients; it may be time to consider trials of AED discontinuation, even in patients with JME. ${ }^{18}$

A recent systematic review and individual participant data metaanalysis, ${ }^{21}$ which was published after closure of our survey and included 1,769 patients, highlighted a highly variable time to AED withdrawal after the last seizure in included studies (mean 33 months, range 3-385). Seizure recurrence occurred in $46 \%$ of patients, with a median follow-up after AED discontinuation of 5.3 years (interquartile range 3.0-10.0). Several predictors of recurrence were identified, particularly age at onset of epilepsy, history of febrile seizures, duration of epilepsy and seizure-free interval, 10 or more seizures before remission, intellectual disability, epileptiform discharges on EEG before discontinuation, and absence of self-limiting epilepsy syndrome. It is difficult to predict how data from this study would have changed the results of the present survey if available earlier, but it is conceivable that more respondents would have probably chosen to wait longer before starting the taper. In fact, an important conclusion of this meta-analysis is that an arbitrary 2year seizure freedom cutoff may be inadequate to predict the risk of relapse, considering that every added seizure-free year lowers this risk. This new insight may be particularly relevant, considering that newer AEDs are in general better tolerated with fewer side effects and potential for interaction with other medications and therefore may be continued for longer periods of time. ${ }^{22}$ On the other hand, the decision to prolong therapy may not be necessary for some patients and the cost/benefit ratio may not be favorable.

Our survey identified major discrepancies in AED withdrawal practices resulting from lack of evidence-based guidelines. This knowledge gap can potentially lead to stopping AEDs with great risks of seizure recurrence in some patients or delaying the discontinuation of AEDs in others who may be excellent candidates to be off AEDs. A multicenter study with appropriate statistical models is needed to analyze epilepsy syndrome, EEG results, and MRI results, among numerous other variables, to allow individualized prediction of seizure recurrence risks after AED discontinuation.

Our study has limitations: sampling was restricted to members of the AAN and readers of the Neurology journals. As with most survey studies, other biases include the degree of reach, the characteristics of the responding sample, and how well it was represented by those who completed the survey. Neurologists from certain countries that had participated in prior studies on AED withdrawal (such as the United Kingdom, for example) may have been underrepresented. The clinical cases and survey questions were intentionally concise, in order to reduce survey fatigue and minimize dropout rate, which inevitably resulted in fewer details that were provided, but at the same time reflected real practice scenarios.

Our worldwide survey showed several discrepancies in choice of AED withdrawal, particularly for JME and TLE after surgery. These results highlight lack of evidence and support the need for further studies of discontinuation with strict inclusion and exclusion criteria for specific types of epilepsy in order to minimize confounders.

\section{Author contributions}

L. Bartolini designed the study and contributed to data analysis and interpretation and drafting and revising of the manuscript. S. Majidi performed the statistical analysis and contributed to interpretation of the data and drafting and revising of the manuscript. M.K. Koubeissi contributed to study design, data analysis and interpretation, and drafting and revising of the manuscript.

\section{Study funding}

No targeted funding reported.

\section{Disclosure}

Dr. Bartolini serves as Section Editor for Neurology: Clinical Practice. Dr. Majidi reports no disclosures. Dr. Koubeissi has received speaker honoraria from and serves on speakers' bureaus for UCB Pharma and Sunovion; serves on the editorial boards of Epilepsy Currents and Functional Neurology and surgery and device editor of Epilepsy.com; is author on patents re: Electrical stimulation of the claustrum for treatment of epilepsy and stimulation of the forno-dorsocommissure (fdc) for seizure suppression and memory improvement; has received a device grant from Medtronic; and has received research support from the Clinical and Translational Science Institute at Children's National (CTSI-CN), George Washington University, and the Coulter Foundation. Full disclosure form information provided by the authors is available with the full text of this article at Neurology.org/cp.

Received September 18, 2017. Accepted in final form December 5, 2017.

\section{References}

1. Cole AJ, Wiebe S. Debate: should antiepileptic drugs be stopped after successful epilepsy surgery? Epilepsia 2008;49(suppl 9):29-34. 
2. Hixson JD. Stopping antiepileptic drugs: when and why? Curr Treat Options Neurol 2010;12:434-442.

3. Strozzi I, Nolan SJ, Sperling MR, Wingerchuk DM, Sirven J. Early versus late antiepileptic drug withdrawal for people with epilepsy in remission. Cochrane Database Syst Rev 2015:CD001902.

4. Practice Current. Available at: neurology.org/collection/practice_current. Accessed February 8, 2018.

5. Beghi E, Giussani G, Grosso S, et al. Withdrawal of antiepileptic drugs: guidelines of the Italian League against Epilepsy. Epilepsia 2013;54:2-12.

6. Braathen G, Anderson T, Gylje H, et al. A comparison between one and three years of treatment in uncomplicated childhood epilepsy: a prospective study: I: outcome in different seizure types. Epilepsia 1996;37:822-832.

7. Verrotti A, Morresi S, Basciani F, Cutarella R, Morgese G, Chiarelli F. Discontinuation of anticonvulsant therapy in children with partial epilepsy. Neurology 2000;55:1393-1395.

8. Lossius MI, Hessen E, Mowinckel P, et al. Consequences of antiepileptic drug withdrawal: a randomized, double-blind study. Epilepsia 2008;3:455-463.

9. Ohta H, Ohtsuka Y, Tsuda T, Oka E. Prognosis after withdrawal of antiepileptic drugs in childhood onset cryptogenic localization-related epilepsies. Brain Dev 2004;26:19-25.

10. Harroud A, Weil AG, Bouthillier A, Nguyen DK. Prognostic tests and antiepileptic drug withdrawal after epilepsy surgery. Can J Neurol Sci 2014;41:409-412.

11. Berg AT, Langfitt JT, Spencer SS, Vickrey BG. Stopping antiepileptic drugs after epilepsy surgery: a survey of U.S. epilepsy center neurologists. Epilepsy Behav 2007; 10:219-222.
12. Schiller Y, Cascino GD, So EL, Marsh WR. Discontinuation of antiepileptic drugs after successful epilepsy surgery. Neurology 2000;54:346-349.

13. McIntosh AM, Kalnins RM, Mitchell LA, Fabinyi GC, Briellmann RS, Berkovic SF. Temporal lobectomy: long-term seizure outcome, late recurrence and risks for seizure recurrence. Brain 2004;127:2018-2030.

14. Berg AT, Vickrey BG, Langfitt JT, et al; Multicenter Study of Epilepsy Surgery. Reduction of AEDs in postsurgical patients who attain remission. Epilepsia 2006;47:64-71.

15. Lachhwani DK, Loddenkemper T, Holland KD, et al. Discontinuation of medications after successful epilepsy surgery in children. Pediatr Neurol 2008;38:340-344.

16. Camfield P, Camfield C. When is it safe to discontinue AED treatment? Epilepsia 2008;49(suppl 9):25-28.

17. Chowdhury A, Brodie MJ. Pharmacological outcomes in juvenile myoclonic epilepsy: support for sodium valproate. Epilepsy Res 2016;119:62-66.

18. Camfield CS, Camfield PR. Juvenile myoclonic epilepsy 25 years after seizure onset: a population based study. Neurology 2009;73:1041-1045

19. Geithner J, Schneider F, Wang Z, et al. Predictors for long-term seizure outcome in juvenile myoclonic epilepsy: 25-63 years of follow-up. Epilepsia 2012;53:1379-1386.

20. Senf P, Schmitz B, Holtkamp M, Janz D. Prognosis of juvenile myoclonic epilepsy 45 years after onset: seizure outcome and predictors. Neurology 2013;81:2128-2133.

21. Lamberink HJ, Otte WM, Geerts AT, et al. Individualised prediction model of seizure recurrence and long-term outcomes after withdrawal of antiepileptic drugs in seizurefree patients: a systematic review and individual participant data meta-analysis. Lancet Neurol 2017;16:523-531.

22. French JA. Withdrawal of antiepileptic drugs: an individualised approach. Lancet Neurol 2017;16:493-494.

\section{Neurology in the Spotlight at 2018 Annual Meeting in Los Angeles}

Registration is now open for the totally flexible, dynamic 2018 Annual Meeting. We'll be shining the spotlight on neurology and what you need to excel in your career. Look for the latest science, education, and networking you won't find anywhere else when the biggest names in neurology and neuroscience convene in Los Angeles April 21 through 27. Learn more and register now at AAN.com/view/AM18. 